\title{
Disruption of the MYC transcriptional function by a small-molecule antagonist of MYC/MAX dimerization
}

\author{
XIAOHONG LU ${ }^{1}$, PETER K. VOGT ${ }^{2}$, DALE L. BOGER ${ }^{2}$ and JOHN LUNEC ${ }^{1}$ \\ ${ }^{1}$ Northern Institute for Cancer Research, Newcastle University, Newcastle upon Tyne, NE2 4HH, UK; \\ ${ }^{2}$ Department of Molecular and Experimental Medicine and Department of Chemistry, The Scripps \\ Research Institute, 10550 North Torrey Pines Road, La Jolla, CA 92037, USA
}

Received October 22, 2007; Accepted November 30, 2007

\begin{abstract}
Inhibition of MYC/MAX dimerization by a smallmolecule antagonist (IIA6B17) has been shown to interfere with MYC-induced transformation of chick embryo fibroblasts, suggesting that the functional inhibitors of the MYC family of oncoproteins have potential as therapeutic agents. In the present study, a functional MYC reporter gene assay has been developed, using a luciferase gene construct under the control of the ornithine decarboxylase $(O D C)$ gene promoter. This luciferase gene construct has been stably transfected into the $M Y C N$ amplified neuroblastoma cell line (NGP) and MYCC-overexpressed neuroepithelioma cell line (NB100). After exposure of the cell lines to IIA6B17 for $24 \mathrm{~h}$, a significant reduction of luciferase activity was only observed in the NB100 cells, with $\mathrm{IC}_{50}$ values of $\sim 28 \pm 9 \mu \mathrm{M}$, indicating that IIA6B17 has cell line-specific activity which may be selective for individual members of the MYC family.
\end{abstract}

\section{Introduction}

The MYC family of proto-oncogenes, which includes $M Y C C$, $M Y C N$ and $M Y C L$, has strong oncogenic potential. Genetic alterations, including gene amplification, chromosome translocation and overexpression resulting in the deregulation of MYC expression have been found in a wide range of human cancers. Elevated expression of MYC, rather than the structural mutation of the protein, contributes to tumorigenesis, although the mechanisms involved are still not fully resolved (1). The $M Y C C$ gene is implicated in a large number of human solid tumors, leukemias and lymphomas and is often associated with poor prognosis. Reciprocal

Correspondence to: Dr John Lunec, Northern Institute for Cancer Research, Newcastle University, Newcastle upon Tyne, NE2 4HH, UK

E-mail: john.lunec@newcastle.ac.uk

Key words: MYC/MAX dimerization, reporter gene assay, MYC inhibitors, cell-based assay chromosomal translocations that activate $M Y C C$ are widely accepted as the initiating events in the natural history of human Burkitt lymphoma (2). The MYCN gene is found to be amplified in 20-30\% of neuroblastoma patients and is associated with rapid tumor progression and poor outcome in this type of cancer $(3,4)$. In addition, $M Y C N$ amplification has also been reported in a number of other tumors, including small cell lung cancers (7\%), alveolar rhabdomyosarcoma $(60 \%)$ and retinoblastoma (20\%) (5-7). Embryonic lethality was reported in mice with targeted homozygous deletion of MYCC or MYCN, while transgenic mouse models of MYCC and $M Y C N$ overexpression were found to develop a range of tumors, suggesting they play a crucial role in embryonic and oncogenic development.

Nuclear MYC proteins form heterodimers with MAX proteins through their conserved bHLH-LZ domains. The MYC/MAX complexes bind specific DNA sequences, such as the E-box sequence CACGTG and transactivate a variety of MYC-target genes, including those involved in cell proliferation, protein synthesis, cell cycle regulation and mitochondrial function. MYC-MAX interaction is essential for MYC-induced cell cycle progression, cellular transformation and transcriptional activation. MAX can also form homodimers or interact with other bHLH-LZ proteins of the MAD family, Mnt1 and Mga. The resulting complexes serve as endogenous MYC/MAX complex antagonists and compete for binding to the same E-boxes as MYC/MAX complexes, though repress rather than activate transcription $(8,9)$. In normal tissues, there is a fine-tuned control of these proteins involved in MYC-target gene transcription and cell proliferation. However, once the $M Y C$ gene is deregulated during oncogenic development, the balances among MYC, MAX and other bHLH-LZ proteins are perturbed. The MYC-target genes are consequently abnormally expressed and certain genes which are usually transcriptionally repressed by endogenous MYC/MAX antagonists in normal circumstances may become activated.

The transcription factor and proto-oncogene $M Y C$ family has been considered as a therapeutic target for cancer treatment (10-12). Inhibition of MYC function can lead to a permanent withdrawal from the cell cycle and terminal differentiation. Downregulation of MYC expression by antisense or siRNA treatment targeted against MYC mRNA, or inhibition of MYC/MAX dimerization by small molecule 
compounds have shown promising proof of principle results with cells in vitro (13-15). These small-molecule antagonists of MYC/MAX dimerization interfere with MYC-induced oncogenic transformation and induce apoptosis in a MYCdependent manner. Although the underlying specific molecular mechanism is not known, it may involve binding of the compounds to a site in either the helix-loop-helix domain or the leucine zipper of either MYC or MAX. The discovery of low molecular weight inhibitors for MYC/MAX dimerization has indicated that functional inhibitors of the MYC family of oncoproteins have potential as therapeutic agents.

In the present study, using a functional MYC reporter gene assay in which the luciferase gene is under the control of the ornithine decarboxylase $(O D C)$ gene promoter, we found that IIA6B17 preferentially inhibits MYCC-dependent transcriptional activity, with little effect on MYCN driven transcription. This cell-based MYC reporter gene assay provides a tool which has the potential to distinguish between MYCC, MYCN and pan-MYC inhibitory activity and will aid in the future development of specific therapeutic strategies in tumors in which $M Y C$ amplification and overexpression have been implicated.

\section{Materials and methods}

Cell lines and IIA6B17. Human neuroblastoma NGP cells (MYCN amplified and overexpressed), neuroepithelioma NB100 cells and colon carcinoma HCT-116 cells (both MYCC-overexpressed) were grown in RPMI-1640 medium (Invitrogen, Paisley, UK) supplemented with $10 \%(\mathrm{v} / \mathrm{v})$ fetal bovine serum at $37^{\circ} \mathrm{C}$ in $5 \% \mathrm{CO}_{2}$ and tested monthly to exclude mycoplasma infection (16). IIA6B17 was developed in the collaborating author's laboratory (13) and was dissolved in DMSO.

Development of stably transfected cell lines. Plasmid pODCpe1 containing an $O D C$ promoter region $(-81$ to +657$)$ upstream of a luciferase reporter gene cDNA (10) was cotransfected with plasmid pCR3 (Invitrogen) into NGP and NB100 cells using transfection reagent FuGene 6 (Roche, Lewes, UK) and grown in G418 antibiotic to select stable transfectants $(400 \mu \mathrm{g} / \mathrm{ml})$. After $48 \mathrm{~h}$ of transfection, the medium was removed and replaced with fresh medium (Promega, Southampton, UK). After growth for two weeks, NGP19 and NB11 clones with the highest luciferase activity were selected for subsequent reporter gene studies. As a nonMYC transcriptional activity control, MYCC-overexpressed HCT-116 cells were stably transfected with a luciferase gene construct under control of the P2 promoter of the human MDM2 gene (pLubP2 and Fig. 1) (17). The clone with the highest luciferase activity was named HCT-116-29. Stably transfected cell lines were maintained in RPMI medium supplemented with $200 \mu \mathrm{g} / \mathrm{ml} \mathrm{G} 418$.

Measurement of MYCN protein expression. Levels of cellular MYC protein were examined by Western blotting according to previously described standard procedures (18). The membrane was incubated with monoclonal antibodies against MYCN (NCM II-100, kindly provided by Dr N. Ikegaki, Division of Oncology, Children's Hospital of Philadelphia,

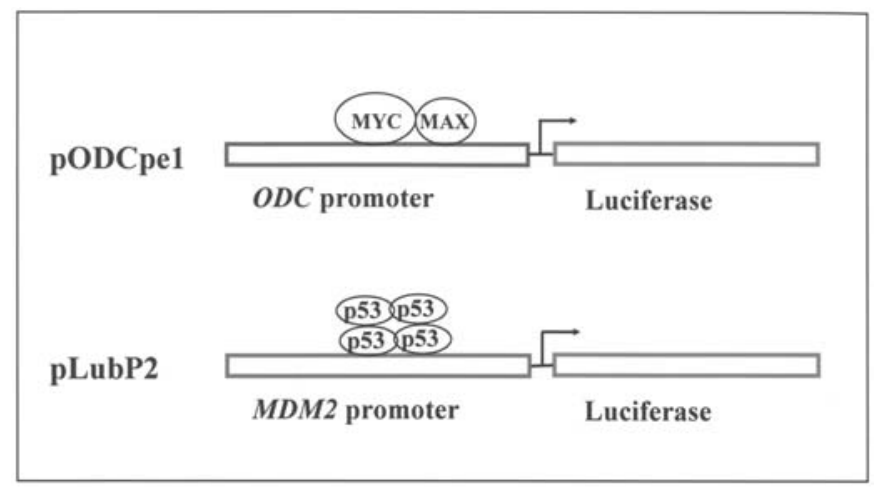

Figure 1. MYC reporter construct pODCpe1 comprising of a luciferase gene controlled by the $O D C$ gene promoter in a pGL3-enhancer vector (Promega) and control plasmid pLubP2 containing a luciferase gene under the control of the $M D M 2$ promoter in a pGL3 basic vector (Promega).

Philadelphia, PA) and MYCC (Novacastra Laboratories Ltd, Newcastle, UK).

Measurement of gene transcript levels. Total RNA was isolated from three cell lines using the RNeasy kit according to the manufacturer's instructions (Qiagen, Crawley, UK). Relative gene transcript levels were determined by multiplex reverse transcriptase PCR. The cDNA was synthesized from $2 \mu \mathrm{g}$ of RNA using SuperscriptII reversetranscriptase (Invitrogen). PCR primer sequences were as follows: MYCN, 5'-GAG GAC ACC CTG AGC GAT TCA-3' and 5'-GAG AGG GGG CGG GAT AGT TGT-3'; MYCC, 5'-GCC CAC CAC CAG CAG CGA CT-3' and 5'-GTG CAT TTT CGG TTG TTG CT-3'; Actin, 5'-CAA CTC CAT CAT GAA GTG TGA-3' and 5'-GCC ATG CCA ATC TCA TCT TG-3'. Multiplex PCR was carried out in a total volume of $25 \mu \mathrm{l}$ and contained $50 \mathrm{ng}$ of each forward and reverse primer sets, $200 \mu \mathrm{M}$ deoxynucleotide triphosphates, onetwentieth of the RT reaction, $50 \mathrm{mM} \mathrm{KCl,} 2.5 \mathrm{mM} \mathrm{MgCl}_{2}$, $10 \mathrm{mM}$ Tris- $\mathrm{HCl}$ (pH 8.3) and 1 unit of AmpliTaq Gold (Applied Biosystems, Cheshire, UK). PCR cycle conditions were as follows: (a) $94^{\circ} \mathrm{C}$ for $45 \mathrm{sec}$; (b) 30 cycles at $94^{\circ} \mathrm{C}$ for $45 \mathrm{sec}, 55^{\circ} \mathrm{C}$ for $45 \mathrm{sec}$ and $72^{\circ} \mathrm{C}$ for $1 \mathrm{~min}$; and (c) $72^{\circ} \mathrm{C}$ for $10 \mathrm{~min}$.

Luciferase activity. Measurements were performed on $10 \mu 1$ samples of cellular lysate in quadruplicate wells using the Dual-light assay kit (Applied Biosystems, Warrington, UK), in conjunction with a microplate Luminometer (Berthold Technologies, Hertfordshire, UK).

Growth inhibition assay. The sensitivity of the cell lines to IIA6B17-induced cell growth inhibition was determined using the sulphorhodamine B (SRB) assay, as described previously (19). Briefly, adherent exponentially growing cells were seeded into 96 -well plates at $3-5 \times 10^{3}$ cells $/ 100 \mu \mathrm{l} /$ well. After $20-24 \mathrm{~h}$ at $37^{\circ} \mathrm{C}$, the medium was replaced with a fresh medium containing IIA6B17 at the appropriate drug concentrations. After drug treatment for $72 \mathrm{~h}$, the cells were fixed in situ by adding Trichloroacetic acid (TCA) to a final concentration of $10 \%$, washed, air dried and stained with sulphorhodamine B. The absorbance per well was measured at 


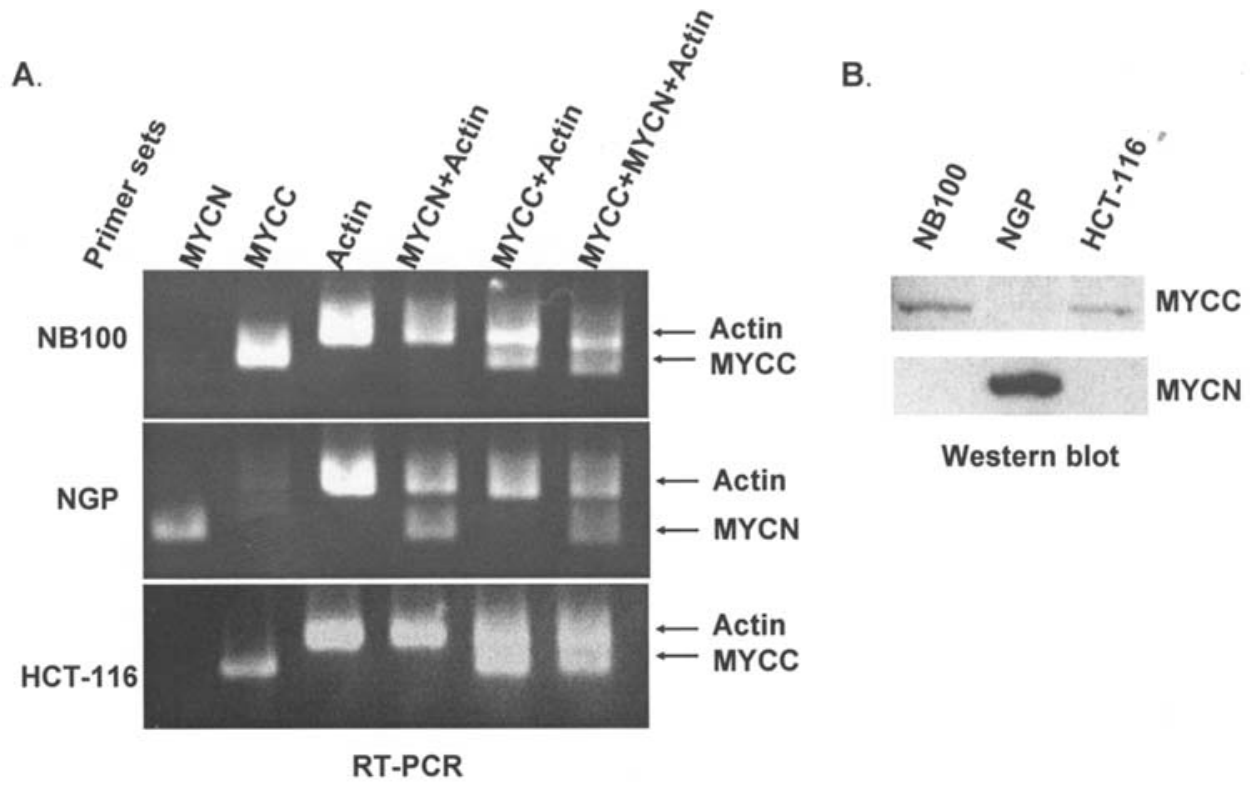

Figure 2. Basal expression levels of MYCC and MYCN transcripts (A) and protein (B) in three cell lines. Reverse transcription and multiplex PCR were performed and a number of combinations of primer sets as indicated were used in each PCR reaction to identify MYC expression status. Western blotting was carried out by using monoclonal antibody against MYCC and MYCN protein as described in 'Materials and methods'.

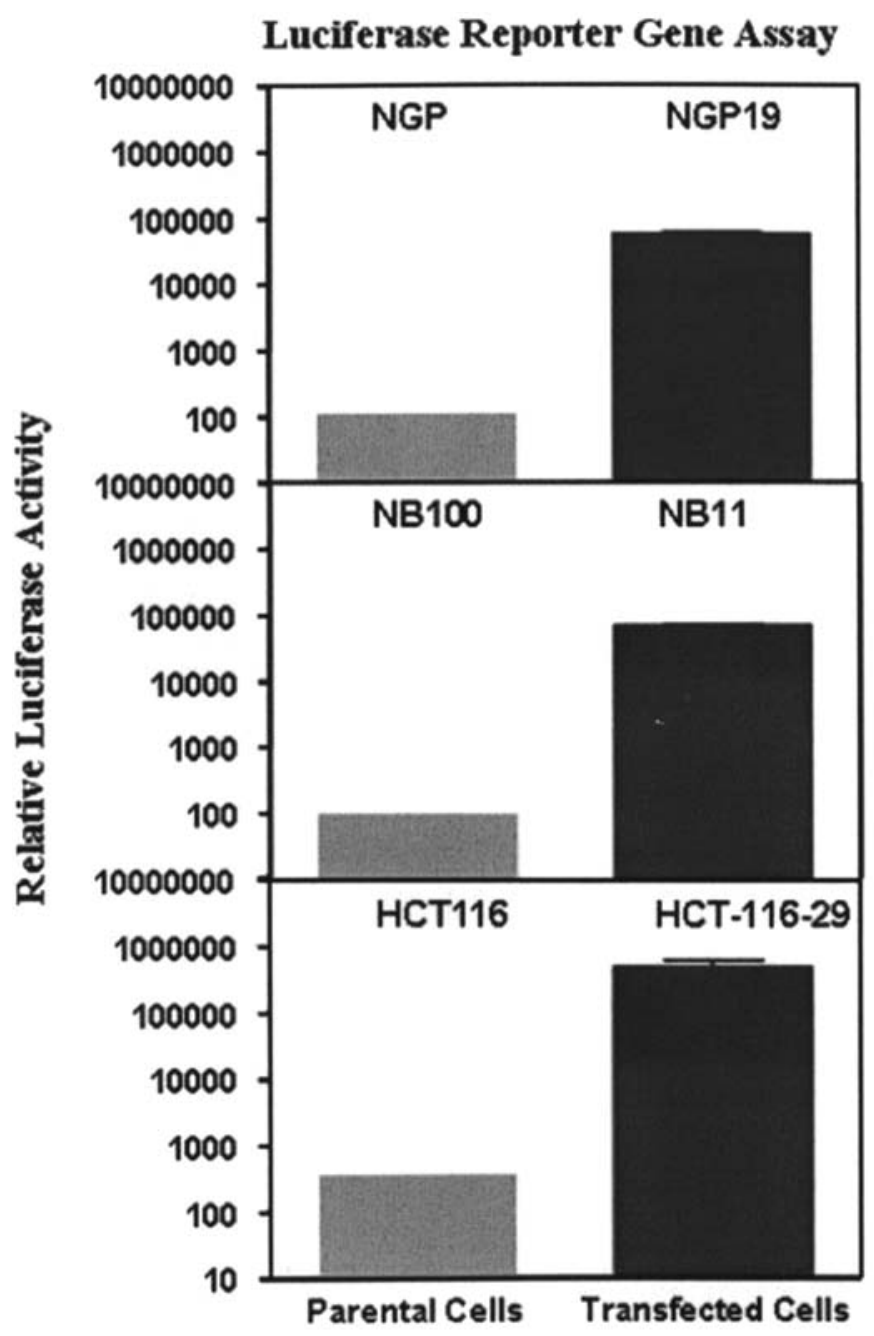

Figure 3. Comparison of luciferase activity in parental cell lines to those in stably transfected NGP19, NB11 and HCT-116-29 cell lines in a luciferase reporter gene assay (Applied Biosystems). An absolute integrated luminometer reading is shown.
$570 \mathrm{~nm}$ on a Spectra MAX250 plate reader (Molecular Devices, Wokingham, UK).

\section{Results}

Differential expression of MYC in three cell lines. The expression levels of MYCN and MYCC in neuroblastoma NGP cells, neuroepithelioma NB100 cells and colon carcinoma HCT-116 cells were examined by reverse transcription and multiplex PCR for MYC transcripts and Western blot for MYC proteins. Differential expression of MYC transcripts and proteins were found in the three cell lines. As shown in Fig. 2A, high levels of $M Y C N$ transcripts were observed only in the $M Y C N$-amplified NGP cell line whereas very little $M Y C C$ transcript was found in this cell line. In contrast, although NB100 and HCT-116 cell lines expressed low or undetectable levels of $M Y C N$, they expressed high levels of $M Y C C$. The relative protein expression levels were found to reflect the $M Y C$ transcripts in these cell lines (Fig. 2B). MYCN protein was found to be highly expressed only in the NGP cells by Western blot, whereas only MYCC proteins were detectable in the other two cell lines, indicating a reciprocal relationship between MYCN and MYCC expression. This reciprocal relationship was also apparent in a wider panel of neuroblastoma and non-neuroblastoma cell lines (data not shown).

Development of stably transfected cell lines. In order to develop stably transfected MYC functional luciferase reporter cell lines, plasmid pODCpe1 containing an $O D C$ promoter driven by a luciferase reporter gene cDNA (10) was cotransfected with plasmid pCR3 (to provide a neomycinresistance gene for selection) into NGP and NB100 cells. Clones with the highest luciferase activities from NGP and NB100 cells were selected and designated NGP19 and NB11 (Fig. 3). As a non-MYC transcriptional activity control, 

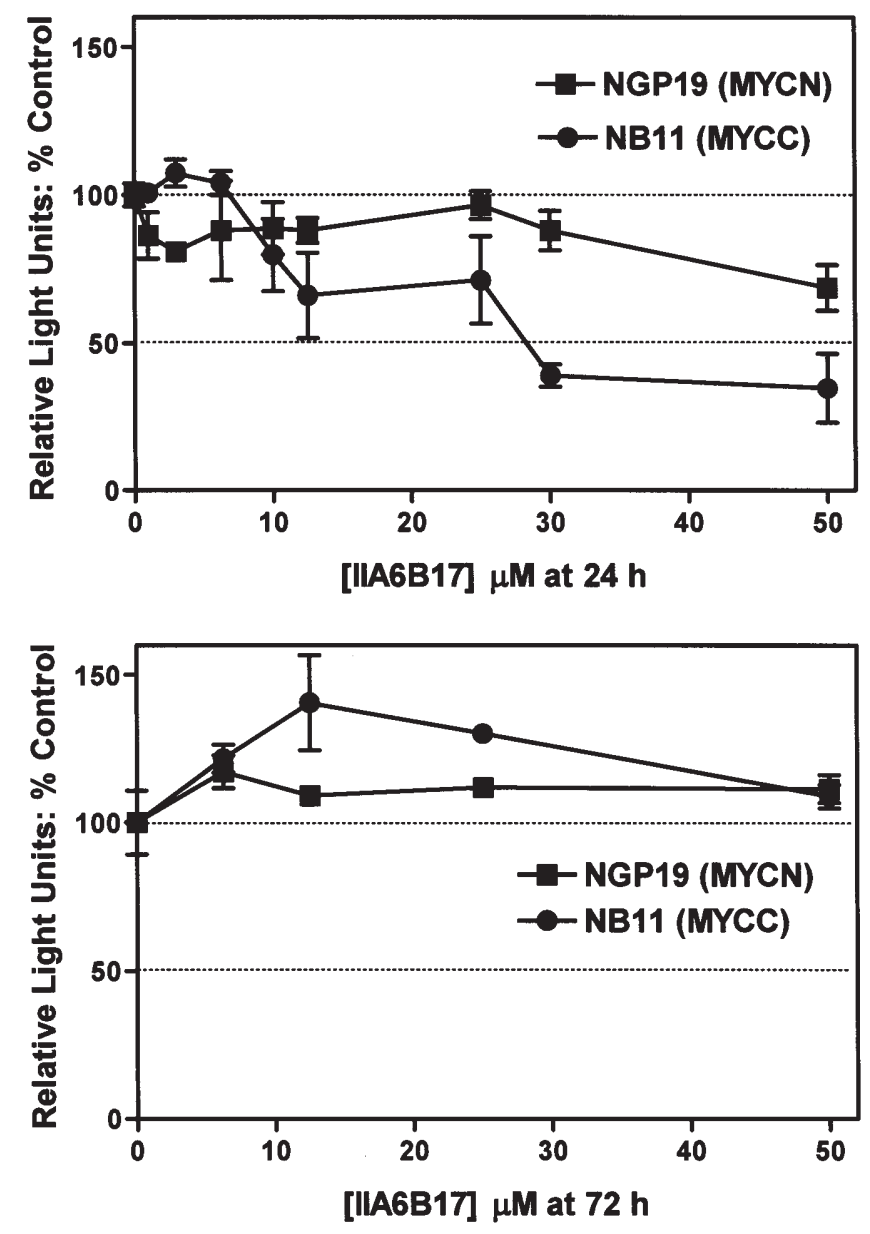

Figure 4. Comparison of luciferase activity in NGP19 (•) and NB11 (•) cells in response to IIA6B17 exposure. Exponential growing cells were exposed continuously to the indicated concentrations of IIA6B17 for 24 and $72 \mathrm{~h}$. Cell lysates $(10 \mu 1)$ from each treatment were assayed for luciferase activity using a luminometer-based procedure as described in 'Materials and methods'.

MYCC-expressing HCT-116 cells were stably transfected with a luciferase gene construct under the control of the $\mathrm{P} 2$ promoter of the human MDM2 gene (pLubP2) (17). The clone with the highest luciferase activity was designated HCT-116-29 (Fig. 3).

Comparison of luciferase activity in response to IIA6B17 exposure in three cell lines. IIA6B17 is a small molecule peptidomimetic compound, selected for inhibition of cell-free MYC/MAX dimerization, which has also been shown to interfere with MYCC-induced transformation of chick embryo fibroblasts (13). In the present study we used a functional reporter gene assay to test whether IIA6B17 has inhibitory activity against MYCC-dependent transcription in intact cells and whether any inhibitory activity also extends to MYCNdependent transcription. The effects on MYCC transcriptional function were tested in NB11 cells and those on MYCN transcriptional function in NGP19 cells. The two cell lines were incubated with IIA6B17 for 24 and $72 \mathrm{~h}$ and luciferase activity was then measured from the cell lysates. After $24 \mathrm{~h}$ of exposure, a significant reduction of luciferase activity to $<50 \%$ of that in the control untreated cells was observed with the NB11 cells $\left(\mathrm{IC}_{50}=28 \pm 9 \mu \mathrm{M}, \mathrm{n}=3\right.$, Fig. 4). In contrast, the luciferase activity in NGP19 cells, although reduced, remained

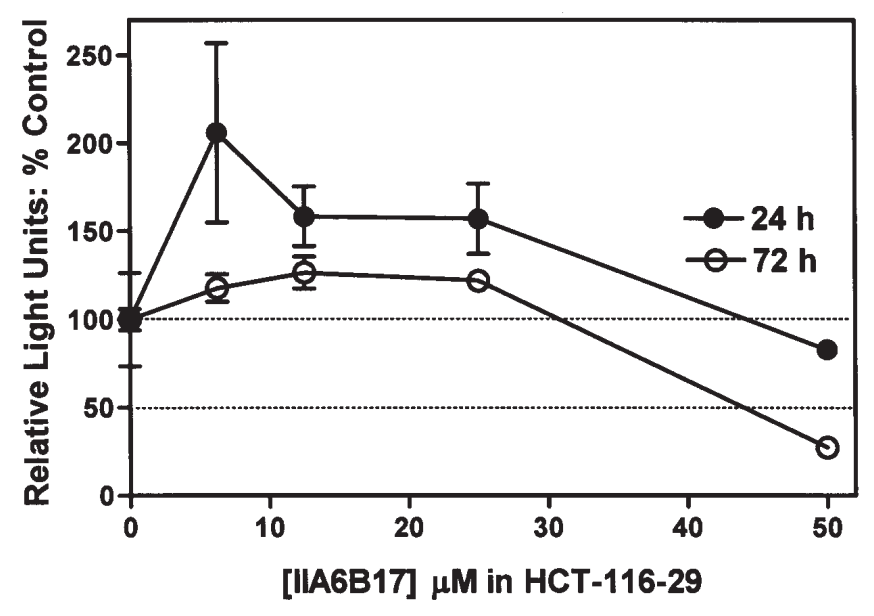

Figure 5. Comparison of luciferase activity in control HCT-116-29 cells in response to IIA6B17 exposure. Exponential growing cells were exposed continuously to the indicated concentrations of IIA6B17 for $24(\bullet)$ and $72 \mathrm{~h}$ ( ). Cell lysates $(10 \mu 1)$ from each treatment were assayed for luciferase activity using a luminometer-based procedure as described in 'Materials and methods'.

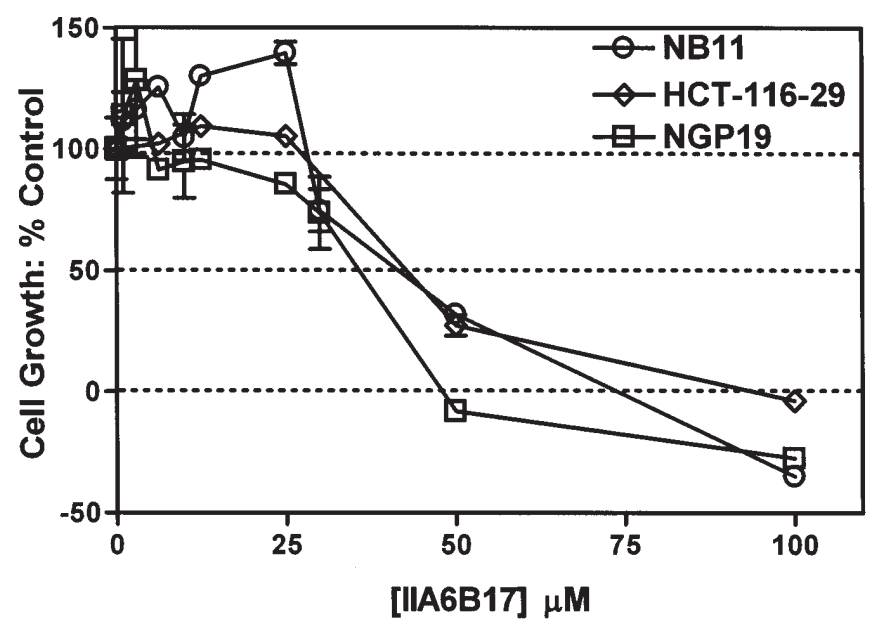

Figure 6. Inhibition of NGP19 ( $\square$ ), NB11 ( $)$ and HCT-116-29 (॰) cell growth by IIA6B17 as determined by the SRB method. Exponentially growing cells were exposed continuously to the indicated concentrations of IIA6B17 for $72 \mathrm{~h}$. Points and error bars are the mean \pm SEM from three experiments.

$>50 \%$ of that in the control untreated cells $\left(\mathrm{IC}_{50}>100 \mu \mathrm{M}, \mathrm{n}=4\right)$, indicating that IIA6B17 preferentially inhibits the function of MYCC in the NB11 cells compared with that of the lesser effect on MYCN-dependent transcription in the NGP19 cells. However, when the two cell lines were incubated with IIA6B17 for $72 \mathrm{~h}$, there was no significant reduction in activity in either cell line relative to the control (Fig. 4), indicating that the inhibition observed after $24 \mathrm{~h}$ was temporary and MYC-dependent transcriptional activity recovers and is slightly elevated compared with the untreated controls.

To evaluate potential non-specific inhibitory effects of IIA6B17 on transcription or luciferase activity in the cell lines, HCT-116-29 cells stably transfected with a luciferase gene construct under the control of the $\mathrm{P} 2$ promoter of the human $M D M 2$ gene (pLubP2) were examined for their luciferase activity in response to treatment with IIA6B17. At low doses 
$(<25 \mu \mathrm{M})$ an increase in luciferase activity relative to the control was observed, which was particularly evident after $24 \mathrm{~h}$ exposure to the compound compared with $72 \mathrm{~h}$. At higher doses $(>50 \mu \mathrm{M})$ an inhibitory effect was observed for 24 and $72 \mathrm{~h}$ exposure, with the latter having a more pronounced effect $\left(\mathrm{IC}_{50}=39 \pm 7 \mu \mathrm{M}\right.$, Fig. 5).

Comparison of IIA6B17-induced growth inhibition in the cell lines. The SRB assay was used to investigate the effect of IIA6B17 on cell proliferation. For all three cell lines, exposure to IIA6B17 for $72 \mathrm{~h}$ resulted in a dose-dependent inhibition of cell proliferation at concentrations $>25 \mu \mathrm{M}$. $\mathrm{GI}_{50}$ values defined as the concentrations of IIA6B17 required to inhibit growth by $50 \%$ were measured as $40 \pm 8,46 \pm 1$ and $43 \pm 3 \mu \mathrm{M}$ for NGP19, NB11 and HCT-116-29, respectively. It was noted that the growth of all three cell lines was inhibited at $72 \mathrm{~h}$ exposure of IIA6B17, irrespective of luciferase activity reduction (Fig. 6), suggesting that IIA6B17 has some nontarget related inhibitory activity on growth at high concentrations.

\section{Discussion}

IIA6B17 is a small molecule antagonist of MYC/MAX dimerization that was previously shown to interfere with MYC-induced oncogenic transformation of chicken embryo fibroblasts in cell cultures (13). In this study, we used a reporter gene assay to test the cellular effect of IIA6B17 on MYCC- and MYCN-dependent transcriptional activity. At high doses $(>25 \mu \mathrm{M})$ there was evidence of an inhibition of MYCN and MYCC transcriptional activity, with the inhibitory effect being greater for MYCC transcriptional function in the NB11 cells expressing high levels of MYCC (Figs. 2 and 4). At low doses $(<25 \mu \mathrm{M})$ a preferential dose-dependent inhibition of MYCC-driven luciferase expression was observed, with little or no effect on MYCN-dependent luciferase expression in the NGP19 cells (Fig. 4). The inhibition of MYCC transcriptional function was observed in the MYCC-expressing NB11 cells (24 h exposure) with a mean $\mathrm{IC}_{50}$ value of $28 \mu \mathrm{M}$. However, there was very little inhibitory activity of IIA6B17 below $30 \mu \mathrm{M}$ in $M Y C N$ amplified NGP19 cells. These results indicate that IIA6B17 preferentially inhibits MYCC function in NB11 cells, with only a modest effect on MYCN function in NGP19 cells at doses of 30-100 $\mu \mathrm{M}$.

It was also noted that the reduction of luciferase activity by IIA6B17 in the NB11 cell line disappeared when the incubation period was extended to $72 \mathrm{~h}$ (Fig. 4), indicating that the inhibition by IIA6B17 is a temporary effect. It was speculated that the inhibition of MYCC function in NB11 cells may result in a feedback stimulation of MYCC expression and this may overcome the initial observed inhibitory effects. It is not known whether the inhibitory effect of IIA6B17 in intact cells is only on heterodimerization of MYCC/MAX; IIA6B17 may also disrupt the interactions of MAX with other HLH-LZ proteins, which are antagonists of MYCC/MAX-induced luciferase activity. The stability of IIA6B17 in the culture medium or inside the treated cells is likely to be a factor. It would be interesting to determine how much intact IIA6B17 is present in the cultured NB11 medium or inside the cells at the end of the exposure time course. IIA6B17 is a first generation compound emerging from a library screen (13) and can now serve as a potential drug development lead to produce improved inhibitors of MYCC/ MAX interactions (20).

In control HCT-116-29 cells in which the luciferase gene was under the control of the $\mathrm{P} 2$ promoter of the human MDM2 gene, the luciferase activity from IIA6B17-incubated cell lysates was not affected after $24 \mathrm{~h}$ of exposure at low doses $\left(\mathrm{IC}_{50}>100 \mu \mathrm{M}\right)$. This supported the specific nature of the effect on MYCC-dependent transcription as indicated by the low dose $(<25 \mu \mathrm{M})$ inhibition of luciferase reporter activity in the NB11 cells. However, when the HCT-116-29 cells were continuously exposed to IIA6B17 at higher doses and for $72 \mathrm{~h}$, a reduction in luciferase activity was observed with a mean $\mathrm{IC}_{50}$ value of $39 \mu \mathrm{M}$. This may indicate a non-specific effect of IIA6B17 on luciferase expression and activity. However, prolonged exposure of the HCT-116-29 cells to IIA6B17 at high doses may, through the inhibition of MYCC, lead to changes of MYCC transcriptional target gene expression levels. One of the MYCC-downstream transcriptional targets is the p53 gene. Inhibition of the MYCC function by IIA6B17 may therefore result in a reduced level of p53 expression in HCT-116-29 cells and indirectly down-regulate the expression of luciferase driven by the $M D M 2$ promoter in the HCT-116-29 cells.

When the three cell lines were examined for their sensitivities to growth inhibition by IIA6B17 exposure for $72 \mathrm{~h}$, there was little difference in $\mathrm{GI}_{50}$ values between them irrespective of initial inhibition of luciferase activity in NB11 cells. NGP 19 cells were marginally the most sensitive with $\mathrm{GI}_{50}$ values at $40 \mu \mathrm{M}$ while NB11 became the most resistant cell line $\left(\mathrm{GI}_{50}: 46 \mu \mathrm{M}\right)$ although the differences between them were not significant. The results indicated that particularly at high concentrations, IIA6B17 might have inhibitory effects on cell growth by mechanisms other than inhibition of MYCC function. One possibility is that at high doses $(>30 \mu \mathrm{M})$ IIA6B17 inhibits HLH-LZ proteins in general within the treated cells, which results in less specific inhibition of cell growth. Nevertheless, the results show that at low doses and shorter $(24 \mathrm{~h})$ exposure times which are not cytotoxic or growth inhibitory, there is a transient specific inhibition of MYCC-dependent luciferase reporter activity which encourages the further development of more potent selective and stable inhibitors from this initial lead.

In conclusion, this study shows that IIA6B17 preferentially inhibits MYCC, with little effect on MYCN in cell-based, MYC reporter gene assays and that it may be possible to discover inhibitors which preferentially target different MYC family members.

\section{Acknowledgements}

We would like to thank Gillian Farnie for providing the HCT-116-29 cell line and Cancer Research UK for financial support for this study.

\section{References}

1. Lutz W, Leon J and Eilers M: Contributions of Myc to tumorigenesis (Review). Biochim Biophys Acta 1: 61-71, 2002. 
2. Zech L, Haglund U, Nilsson K and Klein G: Characteristic chromosomal abnormalities in biopsies and lymphoid-cell lines from patients with Burkitt and non-Burkitt lymphomas. Int J Cancer 17: 47-56, 1976.

3. Brodeur GM, Seeger RC, Schwab M, Varmus HE and Bishop JM: Amplification of $\mathrm{N}$-myc in untreated human neuroblastomas correlates with advanced disease stage. Science 224: 1121-1124, 1984.

4. Berthold F, Sahin K, Hero B, et al: The current contribution of molecular factors to risk estimation in neuroblastoma patients. Eur J Cancer 33: 2092-2097, 1997.

5. Funa K, Steinholtz L, Nou E and Bergh J: Increased expression of $\mathrm{N}$-myc in human small cell lung cancer biopsies predicts lack of response to chemotherapy and poor prognosis. Am J Clin Pathol 88: 216-220, 1987.

6. Driman D, Thorner PS, Greenberg ML, Chilton-MacNeill S and Squire J: MYCN gene amplification in rhabdomyosarcoma. Cancer 73: 2231-2237, 1994.

7. Mairal A, Pinglier E, Gilbert E, et al: Detection of chromosome imbalances in retinoblastoma by parallel karyotype and CGH analyses. Genes Chromosomes Cancer 28: 370-379, 2000.

8. Hurlin PJ, Steingrimsson E, Copeland NG, Jenkins NA and Eisenman RN: Mga, a dual-specificity transcription factor that interacts with Max and contains a T-domain DNA-binding motif. EMBO J 18: 7019-7028, 1999.

9. Xu D, Popov N, Hou M, et al: Switch from Myc/Max to Mad1/Max binding and decrease in histone acetylation at the telomerase reverse transcriptase promoter during differentiation of HL60 cells. Proc Natl Acad Sci USA 98: 3826-3831, 2001.

10. Lu X, Pearson A and Lunec J: The MYCN oncoprotein as a drug development target (Review). Cancer Lett 197: 125-130, 2003.

11. Prochownik EV: c-Myc as a therapeutic target in cancer (Review). Expert Rev Anticancer Ther 4: 289-302, 2004.
12. Vita $\mathrm{M}$ and Henriksson M: The Myc oncoprotein as a therapeutic target for human cancer. Semin Cancer Biol 16: 318-330, 2006.

13. Berg T, Cohen SB, Desharnais J, et al: Small-molecule antagonists of Myc/Max dimerization inhibit Myc-induced transformation of chicken embryo fibroblasts. Proc Natl Acad Sci USA 99: 3830-3835, 2002

14. Mo $\mathrm{H}$ and Henriksson M: Identification of small molecules that induce apoptosis in a Myc-dependent manner and inhibit Mycdriven transformation. Proc Natl Acad Sci USA 103: 6344-6349, 2006.

15. Bell E, Premkumar R, Carr J, et al: The role of MYCN in the failure of MYCN amplified neuroblastoma cell lines to G1 arrest after DNA damage. Cell Cycle (Georgetown, Tex) 5: 2639-2647, 2006.

16. Chen T: In situ detection of mycoplasma contamination in cell cultures by fluorescent Hoechst 33258 stain. Exp Cell Res 104: 255-262, 1977.

17. Liang $\mathrm{H}$ and Lunec J: Characterisation of a novel p53 downregulated promoter in intron 3 of the human MDM2 oncogene. Gene 361: 112-118, 2005.

18. Lu X, Errington J, Curtin NJ, Lunec J and Newell DR: The impact of p53 status on cellular sensitivity to antifolate drugs. Clin Cancer Res 7: 2114-2123, 2001.

19. Lu X, Errington J, Chen VJ, Curtin NJ, Boddy AV and Newell DR: Cellular ATP depletion by LY309887 as a predictor of growth inhibition in human tumor cell lines. Clin Cancer Res 6: 271-277, 2000 .

20. Berg T: Modulation of protein-protein interactions with small organic molecules (Review). Angew Chem Int Ed Engl 42: 2462-2481, 2003. 